\title{
Neurobehavioral Comorbidities in Children with Epilepsy
}

\author{
Modage Anita ${ }^{1}$, Gajre Mona $\mathbf{P}^{1^{*}}$ and Setia Maninder ${ }^{2}$ \\ ${ }^{1}$ Division of Neurology, Epilepsy and Developmental Pediatrics, LTMMC \& LTMGH, Sion, Mumbai, India \\ ${ }^{2}$ Clinical epidemiologist, LTMMC \& LTMGH, Sion, Mumbai, India
}

${ }^{*}$ Corresponding author: Mona P Gajre, Division of Neurology, Epilepsy and Developmental Pediatrics, LTMMC\& LTMGH, Sion, Mumbai, India, E-mail: monapote@yahoo.co.in

Received date: April 06, 2016; Accepted date: May 09, 2016; Published date: May 16, 2016

Copyright: (C) 2016 Anita M, et al. This is an open-access article distributed under the terms of the Creative Commons Attribution License, which permits unrestricted use, distribution, and reproduction in any medium, provided the original author and source are credited.

\begin{abstract}
Objective: To study the prevalence, type and impact of neurobehavioral disorders in children with and without epilepsy.

Methods: After IRB clearance 222 consecutive children with epilepsy, aged 5-12 years were enrolled as cases and 226 age, gender and socio-economic status matched children without epilepsy as controls. Detailed clinical, neurological and academic history was recorded and diagnosis done (case definitions, ILAE 2010). Both groups were administered Strength and Difficulties Questionnaire (SDQ), available in Hindi to screen for abnormal behaviors in 5 domains such as emotional symptoms, conduct problems, hyperactivity, peer relationship problems and prosocial behaviors. The total difficulties scores, individual domain symptom scores and impact scores were obtained. The data was analysed using chi square test or Fisher's exact test and the means between two groups were compared using the t-test.
\end{abstract}

Results: The mean (SD) ages of the cases and controls were 8.56 and 8.6 years respectively $(p=0.459)$. The behavioral comorbidities(epileptics vs non-epileptics) were emotional symptoms $(38.2 \%$ vs $10.6 \%)$, conduct problems $(32.4 \%$ vs $3.5 \%)$, hyperactivity $(19.8 \%$ vs $3.1 \%)$ and peer relationships $(38.2 \%$ vs $6.6 \%) p<0.001$. School irregularity was seen in $25.6 \%$ and $6.1 \%$, school dropouts in $17.5 \%$ and $3.9 \%$ of cases and controls respectively.

Discussion: The prevalence of behavioral comorbidities in epileptics was $39.1 \%$ as compared to $7.9 \%$ nonepileptics $(p<0.001)$. Epileptics had more internalizing behaviors such as emotional problems, poor peer relationships and few externalising ones as hyperactivity and conduct issues. One of the reasons for poor learning was school irregularity due to uncontrolled epilepsy, emotional problems. Existence of emotional problems and poor peer connections in epileptics lead to school dropouts.

Conclusions: Neurobehavioral disorders are significant comorbid conditions seen in children with epilepsy and are a major cause of potentially treatable disability. Awareness of these problems will help target interventions and aid in the holistic management of pediatric epilepsy.

Keywords: Epilepsy; Neurobehavioral disorders; SDQ

\section{Introduction}

Epilepsy is the most prevalent, chronic neurological disorder affecting children and their families [1]. The burden of epilepsy is greater in developing countries [2] with an estimated prevalence of 5.5 cases per 1000 children [3]. The prevalence of associated psychopathology in children with epilepsy (CWE) is 16-77\% [4] and encompasses cognitive impairments, academic concerns and other neurobehavioral disorders [5]. Reasons for psychopathology are multifactorial arising from a complex interplay of multiple etiological variables [6]. The neurological variables include frequent, severe seizures, early age of onset, symptomatic epilepsy and polytherapy [7-9].

Most of the evidence of neurobehavioral disorders in CWE comes from studies done in developed countries and there is limited data of epilepsy and its comorbidities from developing countries. The present study's primary objective was to determine the prevalence and type of neurobehavioral disorders in children with active epilepsy using a standardised questionnaire.

\section{Methods}

This was a prospective case-control study conducted in the epilepsy outpatient department of a tertiary level medical college and hospital located in Mumbai, India over a period of 18 months. After Institutional Review Board (IRB) clearance, consenting children, aged 5-12 years with active epilepsy of $>6$ months duration and average intellectual abilities were enrolled. Children with neurodevelopmental disabilities such as autism spectrum disorders, intellectual disabilities, cerebral palsy, acute symptomatic seizures were excluded from the study. Demographic data, neurological details of epilepsy such as age of onset, its duration, type, frequency, etiology, medications and whether controlled were recorded. Academic details of learning problems, grade retention, school attendance, irregularity and dropouts were noted. 222 consecutive children with epilepsy (CWE) and 226 age, gender and socioeconomic status (SES) matched nonepileptic children were enrolled as cases and controls respectively. 
Page 2 of 6

\section{Case definitions for study enrolment}

The etiologic classification of epilepsy was done as per the International League of Association of Epilepsy (ILAE 2010) on clinical, electrophysiology and neuroimaging criteria [10].

Epilepsy - At least two unprovoked seizures occurring $>24$ hours apart or diagnosis of an epilepsy syndrome

Epilepsy control - A seizure free period of one year or more.

Irregular school attendance - When the criteria of minimum $75 \%$ attendance during the academic year as mandated by State Education authorities were not met.

School dropout - School absentism for an entire calendar month (30days) of the current academic year not due to medical illness.

All cases and controls were administered linguistically and culturally appropriate behavioral questionnaire the Strength and Difficulties Questionnaire to screen for neurobehavioral disorders [11]. The Strength and Difficulties Questionnaire (SDQ) is available in Indian languages and its parent's version was administered. The questionnaire focused on 5 domains i.e. hyperactivity, prosocial behavior, emotional, conduct and peer problems. It screened children with neurobehavioral disorders by measuring the total difficulties score as well as individual symptom scores and total impact scores.

A total difficulties score was generated by summing scores from 4 domains except the prosocial domain. A total difficulties score of 0-13 was normal, 14-16 was borderline and 17-40 was abnormal. An additional supplement was used to assess the impact of neurobehavioral problems on home life, peer-relationships, classroom learning, leisure activities and overall distress. The five impact scores were then summed to generate a total impact score ranging from 0-10. A score of 0 was normal, 1 was borderline and $\geq 2$ was abnormal.

Children with high total difficulties symptom scores and impact scores were referred to a developmental paediatrician/psychiatrist for further evaluation and management.

\section{Statistical Analysis}

Data was entered in Microsoft Excel and analysed using Stata Version 13. The means between two groups were compared using ttest. The proportions were compared using chi square test or Fisher's exact test (for low expected cell counts). A p value of less than 0.05 was considered to be statistically significant.

\section{Results}

Neurobehavioral comorbidities of epilepsy is now accepted as a major cause of treatable disability and an important area of epilepsy research [12]. The results of this study were summed into the following categories: Socio-demographic results presented in Table 1.

The mean (SD) age of children with epilepsy (CWE) cases and nonepileptic controls was 8.56 years and 8.6 years with M:F ratio of 1.2:1 and 0.9:1 respectively. Majority of children were from lower socioeconomic class in both the groups. Hence both groups were age, gender and SES matched. Developmental delay was seen in $13.9 \%$ epileptics more so in the motor domain (45\%). History revealed that $14.4 \%$ epileptic cases during schooling had learning problems, $10.3 \%$ had behavioral problems when compared to non-epileptics $(\mathrm{p}<0.001)$. Furthermore CWE were more likely to have school irregularity and dropouts, irregular attendance was seen in $25.6 \%$ CWE as compared to
$6.1 \%$ non-epileptics $(\mathrm{p}=<0.001)$ and school dropouts were seen in $17.5 \%$ epileptics as compared to $3.9 \%$ non-epileptics $(\mathrm{p}<0.001)$.

\begin{tabular}{|c|c|c|c|c|}
\hline \multicolumn{2}{|l|}{ Characteristics } & \multirow{2}{*}{$\begin{array}{l}\begin{array}{l}\text { Children } \\
\text { with epilepsy }\end{array} \\
\mathrm{n}=222(\%)\end{array}$} & \multirow{2}{*}{$\begin{array}{l}\begin{array}{l}\text { Children } \\
\text { without } \\
\text { epilepsy }\end{array} \\
n=226(\%)\end{array}$} & \multirow[t]{2}{*}{$p$ value } \\
\hline & & & & \\
\hline \multirow{3}{*}{$\begin{array}{l}\text { Age (years)/ } \\
\text { Grade }\end{array}$} & 5-7 (Pre-primary) & $36(16.22)$ & $47(20.8)$ & 0.459 \\
\hline & 7.1-10 (Primary) & $114(51.35)$ & $110(48.67)$ & \\
\hline & 10.1-12 (Middle) & $72(32.43)$ & $69(30.53)$ & \\
\hline \multirow{2}{*}{ Gender } & Male & $121(54.50)$ & $105(46.46)$ & 0.089 \\
\hline & Female & $101(45.50)$ & $121(53.54)$ & \\
\hline \multirow{2}{*}{ Development } & Normal & $191(86.04)$ & $226(100)$ & $<0.001$ \\
\hline & Delayed & $31(13.96)$ & 0 & \\
\hline \multirow{2}{*}{$\begin{array}{l}\text { Learning } \\
\text { problems }\end{array}$} & Present & $32(14.41)$ & 0 & $<0.001$ \\
\hline & Absent & 190 (85.59) & $226(100)$ & \\
\hline \multirow{2}{*}{$\begin{array}{l}\text { Behavioral } \\
\text { problems }\end{array}$} & Present & $23(10.36)$ & 0 & $<0.001$ \\
\hline & Absent & $199(89.64)$ & $226(100)$ & \\
\hline $\begin{array}{l}\text { School } \\
\text { attendance }\end{array}$ & Irregular & $57(25.68)$ & $14(6.19)$ & $<0.001$ \\
\hline School dropouts & Yes & $39(17.57)$ & $9(3.98)$ & $<0.001$ \\
\hline \multirow{2}{*}{ Seizure control } & Controlled & 202 (90.99) & - & \\
\hline & Uncontrolled & $20(9.01)$ & - & \\
\hline
\end{tabular}

Table 1: Baseline demographic and clinical characteristics in children with epilepsy and non-epileptic controls.

\section{Epilepsy related results}

Of 222 cases epilepsy etiology was structural-metabolic in 102 (45.9\%), 105 (47.3\%) were electroclinical syndromes and $15(6.7 \%)$ were others.

Of the structural lesions, 63/102 (61.7\%) had infective granulomas, $15 / 102(14.7 \%)$ had asphyxia brain injuries, $10 / 102(9.8 \%)$ had focal cortical dysplasias, $7 / 102(6.8 \%)$ had chronic stroke, $4 / 102$ (3.9\%) had neurocutaneous syndromes and 3/102 (2.9\%) had insults due postnatal infections.

Of 105 electroclinical syndromes, 50/105 (47.6\%) had benign epilepsy with centrotemporal spikes, 45/105 (42.8\%) had generalized tonic-clonic epilepsy, 5/105 (4.7\%) had childhood absence epilepsy, 2/105 (1.9\%) had late onset childhood occipital epilepsy and 3/105 had myoclonic astatic epilepsy, nocturnal frontal lobe epilepsy and early onset childhood occipital epilepsy respectively.

Majority of the epileptics i.e. $89.1 \%$ were well controlled on monotherapy. Uncontrolled or refractory epilepsy accounted for a total of $9 \%(n=20)$ of the epileptic population. The first drug of choice was sodium valproate in $55.8 \%$, carbamazepine in $18.5 \%$, phenytoin in $10.3 \%$ and phenobarbitone in the rest. Difficult to control epileptics were also on antiepileptics like levetiracetam, nitrazepam, vigabatrin, topiramate etc. Neurobehavioral disorders results were presented in Tables 2 and 3. 
Page 3 of 6

\begin{tabular}{|c|c|c|c|c|}
\hline \multicolumn{2}{|l|}{ SDQ scales } & $\begin{array}{l}\begin{array}{l}\text { Children with } \\
\text { epilepsy }\end{array} \\
\mathrm{n=222}(\%)\end{array}$ & $\begin{array}{l}\begin{array}{l}\text { Children } \\
\text { without } \\
\text { epilepsy }\end{array} \\
\mathrm{n}=226(\%)\end{array}$ & $p$ value \\
\hline \multirow{3}{*}{$\begin{array}{l}\text { Total } \\
\text { difficulties } \\
\text { score }\end{array}$} & Abnormal & 87 (39.19) & $18(7.96)$ & $<0.001$ \\
\hline & Borderline & $36(16.22)$ & $7(3.10)$ & \\
\hline & Normal & 99 (44.59) & 201 (88.94) & \\
\hline \multirow{3}{*}{$\begin{array}{l}\text { Emotional } \\
\text { problems }\end{array}$} & Abnormal & 85 (38.29) & $24(10.62)$ & $<0.001$ \\
\hline & Borderline & $20(9.01)$ & $7(3.10)$ & \\
\hline & Normal & $117(52.70)$ & 195 (86.28) & \\
\hline \multirow{3}{*}{$\begin{array}{l}\text { Conduct } \\
\text { problems }\end{array}$} & Abnormal & $72(32.43)$ & $8(3.54)$ & $<0.001$ \\
\hline & Borderline & 26 (11.71) & $3(1.33)$ & \\
\hline & Normal & $124(55.86)$ & 215 (95.13) & \\
\hline \multirow{3}{*}{ Hyperactivity } & Abnormal & $44(19.82)$ & $7(3.10)$ & $<0.001$ \\
\hline & Borderline & $23(10.36)$ & 0 & \\
\hline & Normal & $155(69.82)$ & 219 (96.90) & \\
\hline \multirow{3}{*}{$\begin{array}{l}\text { Peer relations } \\
\text { problems }\end{array}$} & Abnormal & 85 (38.29) & $15(6.64)$ & $<0.001$ \\
\hline & Borderline & $35(15.77)$ & $10(4.42)$ & \\
\hline & Normal & $102(45.95)$ & 201 (88.94) & \\
\hline \multirow{3}{*}{$\begin{array}{l}\text { Prosocial } \\
\text { behavior }\end{array}$} & Abnormal & $34(15.32)$ & $3(1.33)$ & $<0.001$ \\
\hline & Borderline & $18(8.11)$ & $1(0.44)$ & \\
\hline & Normal & $170(76.58)$ & 222 (98.23) & \\
\hline
\end{tabular}

that classroom learning was affected in $7.2 \%$ epileptics and $0.8 \%$ nonepileptics, unaffected in $78.3 \%$ cases and $98.7 \%$ controls $(\mathrm{p}<0.001)$. Peer relationships was affected in $3.1 \%$ CWE vs $0 \%$ controls and unaffected in $88.7 \%$ cases and $100 \%$ controls respectively $(\mathrm{p}<0.001)$. Similarly family relations and leisure times were affected in $2.7 \%$ only cases and unaffected in controls $(0 \%)(\mathrm{p}<0.001)$ Classroom attendance related results in epileptics (Table 4 ).

\begin{tabular}{|c|c|c|c|c|}
\hline SDQ scales & & $\begin{array}{l}\text { Children with } \\
\text { epilepsy } \\
\mathrm{n=222}(\%)\end{array}$ & $\begin{array}{l}\text { Children without } \\
\text { epilepsy } \quad n=226 \\
\text { (\%) }\end{array}$ & $p$ value \\
\hline \multirow{2}{*}{$\begin{array}{l}\text { Total impact } \\
\text { score }\end{array}$} & $\begin{array}{l}\text { Abnormal } \\
\text { Borderline }\end{array}$ & $68(30.63)$ & $8(3.53)$ & $<0.001$ \\
\hline & Normal & $154(69.37)$ & $218(96.46)$ & \\
\hline \multirow{3}{*}{$\begin{array}{l}\text { Family } \\
\text { relations }\end{array}$} & Abnormal & $6(2.70)$ & 0 & $<0.001$ \\
\hline & Borderline & $42(18.92)$ & $4(1.77)$ & \\
\hline & Normal & $174(78.38)$ & 222(98.23) & \\
\hline \multirow{3}{*}{$\begin{array}{l}\text { Classroom } \\
\text { learning }\end{array}$} & Abnormal & $16(7.21)$ & $2(0.88)$ & $<0.001$ \\
\hline & Borderline & $32(14.41)$ & $3(1.33)$ & \\
\hline & Normal & $174(78.38)$ & 221(97.79) & \\
\hline Friendship/ & Abnormal & $7(3.15)$ & 0 & $<0.001$ \\
\hline \multirow[t]{2}{*}{ peer relations } & Borderline & $18(8.11)$ & 0 & \\
\hline & Normal & $197(88.73)$ & $226(100)$ & \\
\hline \multirow{3}{*}{$\begin{array}{l}\text { Leisure time } \\
\text { activities }\end{array}$} & Abnormal & $6(2.70)$ & 0 & $<0.001$ \\
\hline & Borderline & $20(9.01)$ & $2(0.88)$ & \\
\hline & Normal & 196(88.28) & 224(99.12) & \\
\hline
\end{tabular}

Table 2: Strength and difficulties questionnaire (SDQ-P) domains in epileptics and non-epileptics.

Screening of cases and controls with SDQ-P (parent version) was done, total difficulties score was abnormal in 39\% cases, $7.9 \%$ controls and normal in $44.5 \%$ cases and $88.9 \%$ controls $(\mathrm{p}<0.001)$ (Table 2).

The results on the various domains of SDQ-P were normal/no emotional problems in $52.7 \%$ in CWE and $86.2 \%$ in controls, abnormal high emotional scores were in $38.2 \%$ and $10.6 \%$ in cases and controls respectively $(\mathrm{p}<0.001)$. Normal peer relations were present in $45.9 \%$ and $88.9 \%$, poor peer relationships were present in $38 \%$ epileptics and $6.6 \%$ non-epileptics respectively $(\mathrm{p}<0.001)$. Absent prosocial behaviour was seen in $15 \%$ and $1.3 \%$, normal prosociability was present in $76.5 \%$ and $98.2 \%$ cases and controls $(\mathrm{p}<0.001)$. Of the externalizing behaviors, abnormal conduct problems were seen in $32.4 \%$ CWE and $3.5 \%$ controls whereas $55.8 \%$ cases and $95.1 \%$ controls had normal scores $(\mathrm{p}<0.001)$. Abnormally high hyperactivity scores were seen in $19.8 \%$ CWE versus $3.1 \%$ controls and none were seen in $69.8 \%$ cases and $96.9 \%$ controls $(\mathrm{p}<0.001)$.

The impact of abnormal/borderline behavioral disorders was studied at 3 different settings: home, school and community (Table 3 ).

In $30.6 \%$ cases and $3.5 \%$ controls the impact scores were highly abnormal/borderline in either of the 3 settings $(p<0.001)$. It was found

Table 3: Impact of neurobehavioral disorders in epileptics and nonepileptics at home, school and community.

In CWE regular school attendance was present in $74 \%$. School irregularity was seen in $25.6 \%$ and $6.1 \%$, school dropouts in $17.5 \%$ and $3.9 \%$ of cases and controls respectively. As per the socioeconomic status, irregularity in school was seen in $50.8 \%$ cases of lower SES and $49.1 \%$ from middle SES $(\mathrm{p}<0.8)$. Of the 20 cases with uncontrolled or refractory epilepsy, $60 \%$ had irregular and $40 \%$ had regular school attendance $(\mathrm{p}<0.001)$.

The results of abnormal individual symptom scores (SDQ-P) and school irregularity showed that $63.1 \%$ epileptics had emotional problems $(\mathrm{p}<0.001)$. Abnormal conduct scores, high hyperactivity, poor peer relations, poor prosociality led to low school attendance in $35 \%(\mathrm{p}=0.184), 21 \%(\mathrm{p}=0.342), 45.6 \%(\mathrm{p}=0.271)$ and $19.3 \%(\mathrm{p}=0.211)$ cases respectively. School dropouts were present in $17.5 \%$ of epileptic cases, $58.9 \%$ were of lower SES and $41 \%$ were of middle SES $(\mathrm{p}=0.195)$.Of $\mathrm{n}=20$ uncontrolled epileptics, $25 \%$ had school dropouts $(\mathrm{p}=0.359)$. Emotional problems in epileptics led to dropouts in $69.2 \%$ cases $(\mathrm{p}<0.001)$. Abnormal conduct scores, high hyperactivity, poor peer relations, poor prosociality led to school dropouts in $30.7 \%$ $(\mathrm{p}=0.409), 25.6 \%(\mathrm{p}=0.461), 56.4 \%(\mathrm{p}=0.026)$ and $12.8 \%(\mathrm{p}=0.639)$ cases respectively. 


\begin{tabular}{|c|c|c|c|c|c|c|c|c|}
\hline \multirow{3}{*}{\multicolumn{2}{|c|}{ Characteristics }} & & \multirow{2}{*}{\multicolumn{2}{|c|}{$\begin{array}{l}\text { Children with epilepsy } \mathrm{n=222}(\%) \\
\text { School attendance }\end{array}$}} & \multirow{3}{*}{$\begin{array}{l}\text { p value } \\
\text { Yes } n=39\end{array}$} & \multirow{2}{*}{\multicolumn{2}{|c|}{$\begin{array}{l}\text { Children with epilepsy } n=222 \\
(\%)\end{array}$}} & \multirow[t]{3}{*}{$p$ value } \\
\hline & & & & & & & & \\
\hline & & & Regular $n=165$ & Irregular $\mathrm{n}=57$ & & No $n=183$ & & \\
\hline \multicolumn{9}{|c|}{ A) Demographic variable } \\
\hline \multirow[t]{2}{*}{ i) } & \multirow[t]{2}{*}{ Socioeconomic status } & Lower & $81(49.09 \%)$ & $29(50.88 \%)$ & \multirow[t]{2}{*}{0.816} & $23(58.97)$ & $87(47.54)$ & \multirow[t]{2}{*}{0.195} \\
\hline & & Middle & $84(50.91 \%)$ & $28(49.12 \%)$ & & $16(41.03)$ & $96(52.46)$ & \\
\hline \multicolumn{9}{|c|}{ B) Clinical variable } \\
\hline i) & Seizure control $n=20$ & Uncontrolled & $3(15)$ & $12(60 \%)$ & $<0.001$ & $5(25)$ & $15(75)$ & 0.359 \\
\hline \multicolumn{9}{|c|}{ C) SDQ-P Variables } \\
\hline i) & $\begin{array}{l}\text { Emotional problems } \\
\mathrm{n}=85\end{array}$ & Abnormal & $49(29.70)$ & $36(63.16)$ & $<0.001$ & $27(69.23)$ & $58(31.69)$ & $<0.001$ \\
\hline ii) & Conduct problems $n=72$ & Abnormal & $52(31.52)$ & $20(35.09)$ & 0.184 & $12(30.77)$ & $60(32.79)$ & 0.409 \\
\hline iii) & $\begin{array}{l}\text { Hyperactivity } \\
n=44\end{array}$ & Abnormal & $32(19.39)$ & $12(21.05)$ & 0.342 & $10(25.64)$ & $34(18.58)$ & 0.461 \\
\hline iv) & $\begin{array}{l}\text { Peer relations } \\
n=85\end{array}$ & Abnormal & $59(35.76)$ & $26(45.61)$ & 0.271 & $22(56.41)$ & $63(34.43)$ & 0.026 \\
\hline v) & $\begin{array}{l}\text { Prosocial behaviour } \\
\mathrm{n}=34\end{array}$ & Abnormal & $23(13.94)$ & $11(19.30)$ & 0.211 & $5(12.82)$ & $29(15.85)$ & 0.639 \\
\hline
\end{tabular}

Table 4: Impact of demographic, clinical and SDQ-P characteristics on classroom attendance in epileptic study population.

\section{Discussion}

Psychopathology can precede or follow the development of epilepsy and there is increasing evidence that this bidirectionality reflects the existence of common mechanisms underlying the both, involving frontotemporal limbic structures and a hyperactive hypothalamicpituitary-adrenal axis [13].

Two hundred and twenty two epileptics and 226 non epileptics, age, gender and socio economic status matched and of average intelligence were enrolled as cases and controls respectively. Of CWE, $13.9 \%$ had developmental delay as compared to $0 \%$ controls $(\mathrm{p}<0.001)$. Of $14 / 31$ (45.16\%) had isolated motor delay, $10 / 31(32.25 \%)$ had speech delay and $7 / 31(22.58 \%)$ had both affected. Hanssen-Bauer et al had observed developmental delays in 32\% CWE but of speech/language and academic domains [14]. Studies have noted a varying prevalence of behavioral problems in epileptic children ranging from 19-43\% $[15,16]$ (in our study $10.6 \%$ ) depending on screening tools used and caregivers perception. $14.4 \%$ epileptics had learning problems in school when compared to $0 \%$ controls $(\mathrm{p}<0.001)$. Previous studies had also indicated the academic underachievement in those with epilepsy [17]. We studied the possible sociocultural factors associated with learning problems in our epileptic cohort. Regular consistent schooling with standard structured academic instruction is mandatory for a successful educational outcome. $25.6 \%$ epileptics had irregular school attendance as compared to $6.1 \%$ controls $(\mathrm{p}<0.001)$. Although studies had documented an annual loss of 1-7 school days due to seizures $[18,19] 90.9 \%$ cases in our epileptic cohort were well controlled on medications hinting at other possibilities for school irregularity. A unique, unreported finding was of school dropouts $17.5 \%$ in CWE as compared to $3.9 \%$ controls $(\mathrm{p}<0.001)$.

The primary informant for SDQ-P was mothers (84.6\%) and fathers (15.3\%) in both cases and controls. In our study the prevalence of neurobehavioral comorbidities in children with epilepsy was $39.1 \%$ as compared to $7.9 \%$ non-epileptics $(\mathrm{p}<0.001)$. Indian studies by Choudhary et al. documented a prevalence of comorbidities as $43 \%$ in pediatric epilepsy as compared to non-diseased peers [20] and Alfstad et al. reported a prevalence of $37.8 \%$ in CWE versus $17 \%$ in controls using the SDQ-P questionnaire [9]. A hospital study from Southern India reported a much high prevalence of psychopathology (53.8\%) in CWE albeit with CBCL as a screening tool [21]. CWE had high internalizing behaviors such as emotional symptoms (38.2\%) and poor peer relations (38.2\%) as compared to controls. Of the externalizing behaviors, conduct problems were significantly higher in CWE $(32.4 \%)$ rather than hyperactivity (19.8\%). Studies on poor peer relations [22], conduct issues, hyperactivity, poor prosociability [23] as comorbidities in epilepsy has been well documented in literature. The high prevalence of emotional problems (mood lability, anxiety, low mood, depression) in CWE could be postulated to the associated uncertainity, disease stigma that leads to disruption of child and family routines [24].

\section{Impact of behavioral problems}

The impact of neurobehavioral disorders in our study was also more prominent in CWE compared to controls and was found to affect family relations, classroom learning, peer relations and leisure activities. CWE scored $30 \%$ borderline/abnormal on the impact score 
Page 5 of 6

similar to a study by Alfstad et al. [22]. The burden of epilepsy makes the children and families more psychologically vulnerable with poor coping skills risking them to neurobehavioral disorders.

Schooling is the primary occupation for children. The high association of learning problems in epileptics could partly explain the lower educational level attained by people with epilepsy. In our study irregular school attendance and school dropouts was significantly higher in epileptics with behavioral comorbidities. Furthermore sociocultural factors like socioeconomic status did not impact school attendance. Predictably uncontrolled epilepsy was significantly correlated to poor attendance [18,25] but not school dropouts. Surprisingly presence of emotional symptoms was the most significant domain leading to school irregularity and dropouts. Our country has initiated a wide range of programmes for achieving the goal of Universal Elementary Education (UEE) through several schematic and programme interventions. The Sarva Shiksha Abhiyan (SSA) is being implemented as India's main programme for universalizing elementary education. Its overall goals include universal access, retention, bridging of gender and social category gaps in education and enhancement of learning levels of children. The Right to Free \& Compulsory Education Act 2009 provides justiciable legal framework that entitles all children between the ages of 6-14 years free and compulsory admission, attendance and completion of elementary education with the aim to prevent dropouts. Hence our observation of school dropouts in epileptic children due to emotional problems and poor peer relations is of immense value underscoring the need to focus on this high risk vulnerable population.

\section{Conclusions}

There is a significant prevalence of neurobehavioral disorders in children with epilepsy. The SDQ is a simple, easy to administer tool to assess comorbidities which may be overlooked in a busy office practise. Behavioral disorders often impact family life, friendships and classroom learning. Unattended emotional problems may lead to school irregularity, dropouts and ultimately poor life outcomes. Therefore physician led screening for behavioral comorbidities, counselling services should be a part of multidisciplinary care in the management of pediatric epilepsy services.

\section{Study Limitations}

The study population composed of a hospital, referred children hence generalizing the results to community settings may be challenging.

The study protocol did not include family-related factors (family stress factors, parent/child relationship and family dynamics) and personality traits that could have contributed to the degree of psychopathology in children with epilepsy.

\section{Acknowledgements}

Dr. Mamta Manglani, Professor and Head, Department of Pediatrics, LTMMC \& LTMGH, Sion, Mumbai.

Dean, Dr. Suleman Merchant - LTMMC \& LTMGH, Sion, Mumbai.

\section{References}

1. Bujoreanu IS, Ibeziako P, Demaso DR (2011) Psychiatric concerns in pediatric epilepsy. Pediatr Clin North Am 58: 973-988.
2. Carpio A, Hauser WA (2009) Epilepsy in the developing world. Curr Neurol Neurosci Rep 9: 319-326.

3. Udani V (2005) Pediatric epilepsy-an Indian perspective. Indian J Pediatr 72: 309-313.

4. Plioplys S, Dunn DW, Caplan R (2007) 10-year research update review: psychiatric problems in children with epilepsy. J Am Acad Child Adolesc Psychiatry 46: 1389-1402.

5. Abubakar A, Kariuki SM, Tumaini JD, Gona J, Katana K, et al. (2015) Community perceptions of developmental and behavioral problems experienced by children living with epilepsy on the Kenyan coast: A qualitative study. Epilepsy Behav 45: 74-78.

6. Kraemer HC, Stice E, Kazdin A, Offord D, Kupfer D (2001) How do risk factors work together? Mediators, moderators, and independent, overlapping, and proxy risk factors. Am J Psychiatry 158: 848-856.

7. Høie B, Sommerfelt K, Waaler PE, Alsaker FD, Skeidsvoll H, et al. (2006) Psychosocial problems and seizure-related factors in children with epilepsy. Dev Med Child Neurol 48: 213-219.

8. Berg AT, Smith SN, Frobish D, Beckerman B, Levy SR, et al. (2004) Longitudinal assessment of adaptive behavior in infants and young children with newly diagnosed epilepsy: Influences of etiology, syndrome, and seizure control. Pediatrics 114: 645-650.

9. Besag FM (2004) Behavioral aspects of pediatric epilepsy syndromes. Epilepsy Behav 5: S3-13.

10. Fisher RS, Acevedo C, Arzimanoglou A, Bogacz A, Cross JH, et al. (2014) ILAE official report: a practical clinical definition of epilepsy. Epilepsia 55: 475-482.

11. (2006) Youth in Mind. SDQ Information for researchers and professionals about the Strengths \& Difficulties Questionnaires.

12. Engel J (2013) Chronic behavioral disturbances. Seizures and epilepsy (2nd edn.) New York: Oxford university press, 374-402.

13. Kanner AM (2011) Depression and epilepsy: A bidirectional relation? Epilepsia 1:21-27.

14. Hanssen-Bauer K, Heyerdahl S, Eriksson AS (2007) Mental health problems in children and adolescents referred to a national epilepsy center. Epilepsy Behav 10: 255-262.

15. Novriska D, Sutomo R, Setyati A (2014) Behavioural problems in children with epilepsy. Paediatrica Indonesiana 54: 324-329.

16. Goodman A, Goodman R (2009) Strengths and difficulties questionnaire as a dimensional measure of child mental health. J Am Acad Child Adolesc Psychiatry 48: 400-403.

17. Singh H, Aneja S, Unni KE, Seth A, Kumar V (2012) A study of educational underachievement in Indian children with epilepsy. Brain Dev 34: 504-510.

18. Aguiar BV, Guerreiro MM, McBrian D, Montenegro MA (2007) Seizure impact on the school attendance in children with epilepsy. Seizure 16: 698-702.

19. Baker GA, Hargis E, Hsih MM, Mounfield H, Arzimanoglou A, et al. (2008) International Bureau for Epilepsy. Perceived impact of epilepsy in teenagers and young adults: an international survey. Epilepsy Behav 12: 395-401.

20. Choudhary A, Gulati S, Sagar R, Kabra M, Sapra S. (2014) Behavioral comorbidity in children and adolescents with epilepsy. J Clin Neurosci 21: 1337-1340.

21. Austin JK, Huster GA, Dunn DW, Risinger MW (1996) Adolescents with active or inactive epilepsy or asthma: a comparison of quality of life. Epilepsia 37: 1228-1238.

22. Alfstad KÅ, Clench-Aas J, Van Roy B, Mowinckel P, Gjerstad L, et al. (2011) Psychiatric symptoms in Norwegian children with epilepsy aged 8-13 years: effects of age and gender? Epilepsia 52: 1231-1238.

23. Mona GP, Bhatt T, Shah Z, Shah M, Setia M (2015) Neurobehavioural disorders in childhood epilepsy: a prospective crosssectional survey. Indian journal of basic and applied medical research 4: 127-132.

24. Davies S, Heyman I, Goodman R (2003) A population survey of mental health problems in children with epilepsy. Dev Med Child Neurol 45: 292-295. 
Citation: $\quad$ Anita M, Gajre MP, Setia Maninder S (2016) Neurobehavioral Comorbidities in Children with Epilepsy. J Neurol Neurophysiol 7: 371. doi:10.4172/2155-9562.1000371

Page 6 of 6

25. Aldenkamp AP, Weber B, Overweg-Plandsoen WC, Reijs R, van Mil S (2005) Educational underachievement in children with epilepsy: a model to predict the effects of epilepsy on educational achievement. J Child Neurol 20: 175-180. 